\title{
Social capital and its application to Māori social policy
}

\section{Gina Tompkins}

The social injustice associated with colonisation, as evidenced by poorer health and lower life expectancy of indigenous (Broughton, 1989; Carrington, Shepherd, Li \& Zubrick, 2012; Chantelle, Richmond, Ross, Grace, \& Egeland, 2007; Voyle \& Simmons, 1999) and marginalised immigrant populations (Robert, 1999; Narayan \& Pritchett, 1999) is an indisputable global truth. What is often in dispute is the efficacy behind policy mechanisms implemented to reverse such alarming trends (Klein, 2013). Usually, failure is associated with a 'one size fits all' policy that homogenises ethnic minorities and fails to reflect the inherent diversity within each group (Sachdev, 1990). This argument is reinforced by research that demonstrates negative correlations between ethnic heterogeneity and public spending (Kymlicka \& Banting, 2006). There is growing recognition that deprivation within a social environment is a well-known antecedent of disease (House, Landis \& Umberson, 1988; Utter, Denny, Robinson, Ameratunga \& Milfont, 2011). In particular, Māori are consistently represented in negative health statistics (Sachdev, 1990; Bécares, Cormack, \& Harris,, 2013). A significant proportion of excess Māori morbidity and mortality can be linked to adverse lifestyle factors such as smoking (Blakely, Fawcett, Hunt, \& Wilson, 2006), alcohol (Connor, Broad, Rhem, Steven \& Jackson, 2005), obesity (Rush, 2002) and accidents (Sachdev, 1990). Identifying and improving the social capital of marginalised populations has been propounded as an answer to poor social outcomes (Bourdieu, 1985). Social capital is a concept that seeks to identify the key aspects of the social environment that provide a tangible resource base for the benefit of eligible recipients to facilitate better outcomes for the community as a whole. As social capital places an emphasis on dense kin networks, its near perfect ontological reflection of the Māori worldview begins to emerge. For example, to possess social capital, a person must be related to others, and it is those others, not themselves, who are the actual sources of his or her advantage (Portes, 1998, p. 7).Therefore, social capital offers a framework that can add potential value to policy and practice to address poor Māori statistics.

Coleman (1988) and Bourdieu (1985) were among the first scholars to introduce the concept of social capital, with Bourdieu adopting a resource approach when conceptualising social capital. In 1985 Bourdieu defined social capital as, '... the aggregate of the actual or potential resources which are linked to possession of a durable network of more or less institutionalised relationships of mutual acquaintance or recognition' (Bourdieu, 1985, p. 248). Bourdieu's 1985 definition establishes two fundamental elements. First, social relationships provide individual members with access to resources possessed by associates. Second, these resources will have a finite quality and quantity. Bourdieu's 1985 definition of social capital therefore highlights access to assets gained through membership and networks. This process is alternatively referred to as stratification (Portes, 1998, p. 12). Unfortunately, Bourdieu's 1977 contribution to the field was limited because it was published in French and therefore did not, '... garner widespread attention in the English-speaking world' (Portes, 1998, p. 3). This is lamentable because, '... his definition is arguably the most theoretically refined among those that introduced the term social capital' (Portes, 1998, p. 3). 
In contrast, Coleman's 1988 seminal work took a functional view of social capital as, '... facilitating the action of actors - with the persons or corporate actors - within a social structure' (Coleman, 1988, p. 98). Coleman's approach is important as it laid the foundations for the role of social capital in the creation of human capital (Portes, 1998, p. 5). However, it has been argued that Coleman's approach lacked Bourdieu's finesse creating ambiguity leading to erroneous, 'tautological statements' (Portes, 1998, p. 5). Coleman (1990) remedied his definitional ambiguity by introducing the concept of 'closure'. Closure, is the mechanism through which the observance of group norms and expectations are operated. Coleman (1990) therefore emphasises the necessity of dense networks as a necessary precondition for the development of social capital because it promotes compliance with a set of behavioural norms and expectations. However, to avoid tautological error, it is important to distinguish between the motivations of recipients and of donors in exchanges mediated by social capital (Portes, 1998). In particular, an analysis of donor motivation is important when one takes into consideration that there is neither the agreement nor guarantee of return. Analysing donor and recipient motivations is also important because they illustrate the core processes that the concept of social capital seeks to capture. For Māori, donor motivation is the critical factor in the exercise of key tikanga practice such as manaakitanga and kaitiakitanga (Rangihau 1992). Two types of motivation are consummatory and instrumental.

When an individual observes traffic rules, their behaviour is being influenced by consummatory motivation. Consummatory motivations underlie behaviours that are intrinsically rewarding. Therefore, observing traffic rules is driven by consummatory motivation because an individual is obliged to conform to a set of societal norms and rules and in return can get what they want, in this case, they get to go where they want to go in relative safety. In contrast, instrumental motivation sees, '... social capital as primarily the accumulation of obligations from others according to the norms of reciprocity' (Portes, 1998, p. 7). Unlike consummatory motivations, instrumental motivations are driven by secondary (rather than intrinsic) rewards or goals. The system differs from a normal exchange in two crucial respects. First, the currency with which obligations are repaid may be different from that in which they were incurred in the first place. It may be something as intangible as granting allegiance or approval. Second, any repayment regime is unspecified. Within Māori culture we see this in relation to tuku and koha. Tuku refers to a form of gift, giving, lease or release. Through this process, relationships between the donor and the receiver are expected to continue. A tuku accompanied an unwritten obligation for reciprocity in the form of material gifts, services or help in warfare (Rangihau, 1992). Similarly, the Māori practice 'koha' is another example of financial giving that is based upon an unregulated and unenforceable set of protocols that, nonetheless, compels observance by iwi members based upon instrumental motivation (Barlow, 1991).

Since the pioneering works of Bourdieu and Coleman, consensus is growing that social capital stands, '... for the ability of actors to secure benefits by virtue of membership of social networks or other social structures' (Portes, 1998, p. 6). This definition distinguishes between: a) the recipients of social capital (those making claims); b) the sources of social capital (those agreeing to these demands); and, c) the resources themselves. Where economic capital can be measured in terms of one's net worth, human capital is inside an individual's head, in contrast, social capital is built upon the value of one's relationships. Social capital is distinct from other forms of relationship-based concepts such as social cohesion and social support because it offers a source of resource from which recipients can obtain tangible benefits (Klein, 2013). 
When a community's social environment becomes characterised by structural inequalities such as poverty, the residents' development and subsequent health outcomes are affected. The research is consistent in demonstrating positive correlations between income inequality, the reduction in social capital and negative health statistics (Robert, 1999; Godoy, Reyes-García, Huanca, Leonard, Olvera, Bauchet, \& Seyfreid, 2007; Chantelle, et al., 2007). In particular, research demonstrates the relationship between reduced social capital with increases in teenage pregnancy (Welshman, 2006; Gold, Kennedy, Connell \& Kawachi, 2002), unemployment (Caspi, Entner Wright, Moffitt \& Silva, 1998), risky behaviour in youth (Elgar, Trites, \& Boyce, 2010) youth suicide and mental illness (Migone \& O'Neil, 2005; Haines, Beggs, \& Hurlbert, 2011). Female adolescents demonstrated a particularly strong correlation to depressive symptoms as a result of reduced family social capital (Wu, Xie, Chou, Palmer, Gallaher \& Anderson Johnson, 2010). Given this relationship between a reduction in social capital and poor social outcomes, the logical hypothesis is that an inverse relationship between strengthening social capital and improving negative statistics should follow. However, this inverse relationship and therefore social capital's utility in improving social statistics among ethnic minorities, is heavily debated within social service and public health research.

In arguing that, '... there cannot be a social capital theory of society' (Das, 2006, p. 65) opponents challenge social capital's ontological ability to formulate theoretical foundations. The basis for the criticism is that social capital is conceptualised in the literature as, '... class neutral and is therefore under theorised' (Das, 2006, p. 82) where social capital must be viewed in a class context to obtain legitimacy (Das, 2006). However, Das (2006) does recognise that social capital's norms of trust and reciprocity discourage, '... micro level free rider behaviour and develop meso level informal mechanisms of support' (Das, 2006, p. 74).

On a contextual level, there is significant debate as to whether social capital should be properly confined to only a micro level analysis (Makino \& Starfield, 2001). This is predicated on the argument that individuals, not communities, build trust (Hyyppa \& Maki, 2003, p. 359). However, recent research in New Zealand demonstrates that the partnership between two community-based agencies, (i.e. Ngai Tahu law centre and the Dunedin community law centre), was founded upon a relationship of reciprocity and trust (Walker, 2007) that continues to exist even though the personalities change.

The current consensus is that social capital can be used either individually or collectively within both micro (Chappell and Funk, 2010) and meso contexts (Carrington, et al., 2012; Putnam, 1993). In recent years, social capital as a macro framework is used to analyse global relationships between countries such as New Zealand and Chile (Barton, Gwynne, \& Murray, 2007). The application of the concept at a macro/global level is gaining academic traction (Mahdavi \& Azizmohammadlou, 2013). However, there is argument that applying social capital at a global level is extending the concept beyond its original limits (Portes, 1998).

A final area of fertile contention relates to how social capital should be measured, i.e. whether it should be measured as an independent, mediating or dependent variable (Carpiano, 2006). However, recent research indicates that social capital contributes to areas such as health beyond other forms of social support to such an extent that the, '... variables social support and social capital, are two independent relationship-based causes of disease that require different instruments of measurement' (Song \& Lin, 2009, p. 149). Song and Lin criticise previous research as equating social capital with other relationship-based concepts 
such as social networks, social support, social integration and social cohesion. These lack of distinctions, '... endangers the added value of social capital theory' (Song \& Lin, 2009, p. 152).

The outcome of such debates directly impact upon Māori public health policy and social work practice. The potential for social capital to add value and insight into social work policy and practice is growing in recognition. For example, research has examined the relationship between challenging and severely impoverished social environments and the buffering role of social capital in mitigating the stress (Carpiano \& Kimbro, 2012), physical health outcomes and independence (Modie-Moroka, 2009) associated with potentially toxic social environments. As a result of this research, it was recommended that there is a specific need to include effective and community-specific measures to examine the distribution and use of social capital to aid the formulation of policy and programmes to combat social exclusion and enhance health and social outcomes (Modie-Modoka, 2009). Given the literature consistently demonstrates a positive correlation between income inequality and poor health outcomes, Groot, Henriëtte Maassen van, \& Bernard (2007) have demonstrated social capital's ability to address this resulting social injustice by compensating for income variations. This research confirms previous findings that social capital was significantly correlated with improved measures of satisfaction and social well-being. What is unique about this research is that it quantified the difference in monetary terms. As a result, '... the compensating variation of social capital in terms of money is sizeable' (Groot et al, 2007, p. 205).

Bécares et al. (2013) have recently demonstrated a positive correlation between Māori ethnic density (i.e. large numbers of Māori living near to one another) and improving health outcomes by, '... decreasing reporting of poor self-rated health and doctor-diagnosed common mental disorders' (Bécares et al., 2013, p. 76). Furthermore, once area deprivation was controlled for, this correlation became statistically significant. The conclusion reached is that the detrimental effects of area deprivation have prevented previous research from demonstrating the positive effects associated with Māori ethnic density and social capital. Furthermore, social capital offers a valuable source of protective and resilience factors against structural racism. A feature the authors recognise as critical given that racist practices have created existing health and socio-economic inequalities in the first place. In addition, racism currently, '... maintains the unequal distribution of concentrated poverty in areas of high Māori density' (Bécares et al., 2013, p. 78). As a result, the primary focus for any public policy that aims to improve Māori social outcomes will include the elimination of institutional racism (Bécares et al., 2013). One example of structural racism is illustrated in the conceptual differences of Māori between Parliament and the legislature. For Parliament, Māori tend to be conceptualised as a racial group. In contrast, the legislature (who have the responsibility for drafting policy) conceptualise Māori as a cultural group. This difference has significant impact upon policy development and delivery because Māori become conceptualised, '... as either racial or cultural - but not both' (Gershon, 2008, p. 429). If Parliament views Māori as a racial group, this homogenous perspective fails to take into account the diversity within each iwi because it is embedded in their cultural expression or practice. This homogeneity therefore creates myopic policies that will not suit all Māori - so these policies are bound to fail. This simplified approach creates confusion, resulting in poorly drafted policy, practice and subsequent service delivery.

Analysing the relationship between health and social environments has additional policy ramifications. For example, if a health policy is predicated on the assumption that the relationship between policies governing education, employment and income transfer positive 
health outcomes, but in reality there is only a weak association between education and health, then government investment in education is unlikely to result in significant improvement in indigenous health or to reduce health disparities. (Carrington, 2012). Not only does the formulation of effective indigenous social policies need to recognise the social and cultural factors that play a critical role in indigenous health well-being, but simultaneously, it needs to accept that these factors are not necessarily the dominant determinants of health. For example, according to the Māori worldview, iwi and kinship network, cultural continuity, and connection to traditional lands enables Māori to maintain spirituality central to their notion of health and well-being (Barlow, 1991). This spiritual view and close connection to traditional land is contrary to that held by Western hegemonic health discourse. By adopting the Māori worldview, social capital can influence the development of indigenous social policy and practice in two functional ways. First, social capital provides a source of parental and kin support. Second, it provides a source of benefits through extra familial networks.

\section{Parental support}

Ethnic minorities tend to lack social capital beyond their family ties. Immigrant families in particular, compensate for the absence of external social capital by emphasising social capital in the form of family support. This inevitably includes, '... preservation of the cultural orientations of their home country' (Portes, 1998, p. 14; Hagan, MacMillian \& Wheaton, 1994). Problems arise when interactions within urban areas become so saturated that these ties seldom reach outside the geographical area, thereby depriving the inhabitants of sources of information about employment, education, health and ways to attain them (Wilson, 1996). Not only do members become cut off from information about the outside world, but they develop alternative cultural styles that adversely influence health behaviour. For example, within these types of areas, teenage pregnancy is regarded as a culturally acceptable way to gain adult status and independence (Perry, Williams, Wallerstein \& Waitzkin, 2008). This is consistent with contagion and epidemic models that suggest people's behaviour is influenced by the norms and values of those around them (Crane, 1991; Jencks \& Mayer, 1990).

This causes debate as to whether social policy should target micro or meso level interventions. For example, poverty is seen as a major cause of poor health outcomes on ethnic minorities. When developing policies to address poverty, some argue that community action is too heavily emphasised and that greater attention needs to be paid at the micro level, i.e. creating jobs, raising levels and the redistribution of income through taxation policy. However, this criticism fails to take into account the distinction between the '... state of poverty (i.e. lack of money) and the culture of poverty (i.e. a lifestyle decision)' (Welshman, 2006, p. 270). The implication for this distinction is that health behaviour is largely influenced by its cultural and sub-cultural context. Once a culture of poverty is established, it tends to perpetuate itself through generations (Welshman, 2006). Changing behaviour therefore requires a cultural solution developed and delivered as a community-based intervention. Proponents of this approach argue that community interventions are not optional, but are necessary to improve overall individual and population health (Robert, 1999).

A significant proportion of the research in this area focuses on nuclear and single-parent families. The conclusions reached include: intact families and those where one person has the primary task of rearing children, possess more of this form of social capital than single-parent families or those where both parents work (Hao, 1994). Social capital is greater 
in two-parent families and those with fewer children, because parents may have higher aspirations for their young (Portes, 1998, p. 11; Hao, 1994). Other researchers attribute lower social capital in single-parent families due to the fact that these families tend to change residences more often, leading to fewer ties to other adults in the community (McLanahan \& Sandefur, 1994). Alternatively, research argues that intact families foster greater parental attention and spend more time with their children than single families, thereby developing higher levels of social capital (Portes, 1998, p. 11). The research in this area of social capital seems to be dominated by creating stereotypes and binary oppositions. For example, the literature consistently made inferences that parents of intact families spend more time with their children, or had higher aspirations for their children than single parents. This therefore leads to the logical fallacy that single parents, in contrast to two-parent families, spend less time with their children and have lower aspirations for their young. The research did not make any correlations between either aspirations for young, or time spent with children, and family structure. In addition, the correlation between changing residences and family structure was untested. This area represents a gap in the research because it excludes contemporary family arrangements such as the 'blended family' or 'shared care arrangements' between separated parents. In particular, it excludes situations that are characteristic of indigenous and Pacific Island communities such as extensive contact with extended family members or situations where there are multiple families living within the same residence.

\section{Extra familial networks}

Social capital's emphasis on extra familial networks that develop due to collaboration, partnership, trust and reciprocity represents its best ontological fit for Māori due to Māori cultural norms and is assisted by its parallels to the Treaty of Waitangi. The role that the Treaty plays in Māori social policy can take one of two broad approaches (Hayward, 2004). First, an approach based on the actual wording of the Treaty. Proponents of this approach argue that the Treaty makes specific references to Māori well-being, in both Māori and English translations. This interpretation is consistent with the political and historical concerns that contextualised the Treaty in 1840. In particular, article 2 places an added emphasis on Māori control over things Māori (Hayward, 2004). The use of the Māori words 'taonga katoa' implies connection between the Treaty and Māori social and economic development. Some argue that the Treaty affords Māori additional rights (Hayward, 2004). However, one thing is clear that at the very least, Māori were to enjoy the same health and well-being is nonMāori. The historic and current trends in negative Māori health statistics evidence ongoing breaches of this fundamental right (Ellison-Loschmann \& Pearce, 2006). Interpretations of the meaning that rely purely on the words used in drafting the Treaty are subject to ongoing conjecture and judicial process (Hayward, 2004). The second approach therefore involves a principled approach under the Waitangi Tribunal Act to mitigate interpretation issues. In 1988, a set of principles directly applicable to health and social policy were developed (Royal Commission on Social Policy, 1988). These are the principles of partnership, protection and participation (Hayward, 2004).

The principle of protection is in direct reference to the preamble, Article 2 and 3 of the Treaty (Hayward, 2004). This principle is designed to eliminate inequities at all levels and to ensure that social outcomes for Māori and non-Māori are the same (Voyle \& Simmons, 1999). Historically, Māori health policy was developed through generic frameworks derived from the notion that cultural factors played only a minor role in the delivery of health services. 
Māori health gains were limited as a result (Williams, 2012; Lancashire, 2010). The most reasonable approach to lift the health status of Māori is through implementing a range of mechanisms and policies in a manner consistent with the notion of active protection (Ellison-Loschmann \& Pearce 2006). Strategies that focus on a particular ethnic group tend to focus on socio-economic factors or contributors that are known precipitators of poor health (Lancashire, 2010). A focus on socio-economic factors alone does take into account the role of culture as a determinant of health and well-being (Williams, 2012; Grant, 2008).

The principle of participation is linked to the idea of tino rangatiratanga and the obligation of Māori participation in the delivery of services. Traditionally, the role of Māori was confined to that of a consumer (Lancashire, 2010). One determinant associated with poor health outcomes for Māori is access to the health care that they need. Despite efforts to improve access, care pathways are uneven, and in many cases, Māori do not receive the type of care they require (Hall \& Sibthorpe, 2003) and their access to needed social services may be equally problematic. Assertive and energetic outreach programmes need to be incorporated in Māori social policy to raise the current level of Māori access to even lower-level primary health and social service organisations (Williams, 2012). For example, one characteristic outcome from the Māori renaissance has been the spread of the marae from rural to urban spaces. The use of urban marae in community development projects has been influential in social policy delivery (Voyle \& Simmons, 1999). This function of social capital facilitates the collaboration between mainstream professional groups and Māori to facilitate an empowerment and self determination to foster the advancement of health and well-being of minority indigenous groups. (Voyle \& Simmons, 1999). Whaiora marae (an urban marae in Otara) was instrumental in obtaining assertive outreach to Māori with diabetes (Voyle \& Simmons, 1999).

\section{Conclusion}

Sociability cuts both ways. While it can be the source of public good, it can also lead to public bad, e.g. mafia families, prostitution and gambling rooms, and youth gangs offer so many examples of how in bitterness, social structures can be turned to less than socially desirable ends. Social capital is not without its disadvantages. For example, the same strong ties that bring benefits to members of the group commonly enable it to bar others from access. This exclusion obviously represents cultural advantages as it offers protective factors against encompassment and assimilation. However, exclusion comes at a cost. It restricts the group from obtaining social capital from sources external to it. Existing members are therefore the sole source of social capital. This is a problem in fields such as health, where professional input irrespective of its pedigree, is a critical factor when developing indigenous health policies. In addition, exclusion leads to saturation and group solidarity. Group solidarity is cemented by a common experience of adversity and opposition to mainstream society. As a result, the group can become characterised by downward levelling norms, which is usually preceded by lengthy periods, often lasting generations. For Māori, this is a very real risk given their historical experience of oppression and discrimination. This historical experience underlines the emergence of an oppositional stance towards the mainstream and solidarity grounded in the common experience of subordination. This could partly explain Māori lack of access to even lower-level primary health services and why deficit approaches can affect their involvement in services. This lack of access is not due to ignorance, but rather to a historical foundation of suspicion of the dominant mainstream Pākehā culture. Social capital 
is an ontological reflection of the Māori worldview. When looking into that reflection, Māori see principles of trust, reciprocity, collaboration and more importantly, whanau.

\section{References}

Barlow, C. (1991). Tikanga Whakaaro: Key concepts in Māori culture. Auckland: Oxford University Press.

Barton, J. R., Gwynne, R. N., \& Murray, W. E. (2007). Competition and co-operation in the semi-periphery: Closer economic partnership and sectoral transformations in Chile and New Zealand. The Geographical Journal, 173, 224-241.

Bécares, L., Cormack, D., \& Harris, R. (2013). Ethnic density and area deprivation: Neighbourhood effects on Maori health and racial discrimination in Aotearoa/New Zealand. Social Science \& Medicine, 88, 76.

Blakely, T., Fawcett, J., Hunt, D., \& Wilson, N. (2006). What is the contribution of smoking and socioeconomic position to ethnic inequalities in mortality in New Zealand? The Lancet, 368(9529), 44-52.

Bourdieu, P. (1977). Les trois etats du capital culturel. Actes Rech Sci.Soc., 30, 3-6.

Bourdieu, P. (1985). The forms of capital. In Richardson, J.G. (Ed.). Hamburg theory and research for the sociology of education, pp. 241-258. New York: Greenwood.

Broughton, H. R. (1989). The well-being of the Maori. World Health, June 20.

Capriano, R.M. (2006). Toward a neighbourhood resource-based theory of social capital for health: Can Bourdieu and sociology help? Social Science and Medicine, 62, 165-175.

Carpiano, R. M., \& Kimbro, R. T. (2012). Neighborhood social capital, parenting strain, and personal mastery among female primary caregivers of children. Journal of Health and Social Behavior, 53(2), 232-47.

Carrington, C.J., Shepherd, B., Li, J., \& Zubrick, S. (2012). Social gradients in the health of indigenous Australians. American Journal of Public Health, 102(1), 102-116.

Caspi, A., Entner Wright, B.R., Moffitt, T. E., \& Silva, P. A. (1998). Early failure in the labor market: Childhood and adolescent predictors of unemployment in the transition to adulthood. American Sociological Review, 63(3), $424-451$.

Chantelle, A., Richmond, M., Ross, N., Grace, M., \& Egeland, G.E. (2007). Social support and thriving health: A new approach to understanding the health of indigenous Canadians. American Journal of Public Health, 97(9), 1827-1833.

Chappell, N. L., \& Funk, L. M. (2010). Social capital: Does it add to the health inequalities debate? Social Indicators Research, 99(3), 357-373.

Coleman, J.S. (1988). Social capital and the creation of human capital. American Journal of Sociology, 94, 95-121.

Coleman, J.S. (1990). Foundations of social theory. Chicago: University of Chicago Press.

Connor, J., Broad, J., Rehm, J., Stephen, V. H., \& Jackson, R. (2005). Patterns of drinking and estimates of alcohol-related mortality in New Zealand. Contemporary Drug Problems, 32(4), 527-546, 497.

Crane, J. (1991). The academic theory of ghettoes and neighborhodd effects on dropping out and teenage child rearing. American Journal of Sociology, 96, 1236-1259.

Das, R. J. (2006). Putting social capital in its place. Capital \& Class, (90), 65-88.

Ellison-Loschmann, L., \& Pearce, N. (2006). Improving access to health care among New Zealand's Maori population. American Journal of Public Health, 96(4), 612-7.

Elgar, F.J., Trites, S. J., \& Boyce, W. (2010). Social capital reduces socio-economic differences in child health: evidence from the Canadian Health Behaviour in School-Aged Children Study. Canadian Journal of Public Health/Revue Canadienne de Sante'e Publique, 101 (3) S23-S27.

Gershon, L. (2008). Being explicit about culture: Maori, neoliberalism, and the New Zealand parliament. American Anthropologist, 110(4), 422-431.

Godoy, R., Reyes-Garcia, V., Huanca, T., Leonard, W. R., Olvera, R. G., ..., Seyfried, C. (2007). The role of community and individuals in the formation of social capital. Human Ecology, 35(6), 709-721.

Gold, R., Kennedy, B. P., Connell, F., \& Kawachi, L. (2002). Teen births, income equality, and social capital: Developing an understanding of the causal pathway. Health $\mathcal{E}$ Place, 8, 77-83.

Grant, S. (2008). Contextualising social enterprise in New Zealand. Social Enterprise Journal, 4(1), 9-23.

Groot, W., Henriëtte Maassen van, d. B., \& Bernard, v. P. (2007). The compensating income variation of social capital. Social Indicators Research, 82(2), 189-207.

Hagen, J., MacMillian, R., \& Wheaton, B. (1996). New kid in town: Social capital and the life course effects of family migration and children. American Sociology Review, 61, 368-385

Haines, V. A., Beggs, J. J., \& Hurlbert, J. S. (2011). Neighborhood disadvantage, network social capital, and depressive symptoms. Journal of Health and Social Behavior, 52(1), 58-73.

Hall, G., \& Sibthorpe, B. (2003). Providing health services to indigenous peoples. RMF, 327, 408-409.

Hao, L. (1994). Kin support, welfare, and out-of-wedlock mothers. New York: Garland.

Hayward, J. (2004). Te Tiriti o Waitangi. In Ka'ai, T.M., Moorfield, J.C., Reilly, M.P.J. \& Mosley, S. (Eds). Ki te whaiao: An introduction to Māori culture and society. Auckland: Pearson Education.

House, J.S., Landis, K.R., \& Umberson, D. (1988). Social relationships and health. Science 241, 540-545.

Hyyppa, M.T., \& Maki, J. (2003). Social participation and health in a community rich in stock of social capital. Health Education Research, 18(6), 770-779. 
Jencks, C. \& Mayer, S.E. (1990). The social consequences of growing up in a poor neighbourhood. In Lynne, L.E., \& McGeary M.G.H. (Eds). Inner-city poverty in the United States. Washington, DC: National Academic Press.

Klein, C. (2013). Social capital or social cohesion: What matters for subjective well-being? Social Indicators Research, 110(3), 891-911.

Kymlicka, W., \& Banting, K. (2006). Immigration, multiculturalism, and the welfare state. Ethics E International Affairs, 20(3), 281-304, 401.

Lancashire, R. (2010). New Zealand cuts health spending to control costs. Bulletin of the World Health Organization, 88(10), 723-724.

Mahdavi, A., \& Azizmohammadlou, H. (2013). The effects of industrialization on social capital: The case of Iran. International Journal of Social Economics, 40(9), 777.

Makino, J., \& Starfield, B. (2001). The utility of social capital in research on health determinants. Milbank Quarterly, 79(3), 387-427.

McLanahan, S. \& Sandefur, G. (1994). Growing up with a single parent: What hurts, what helps. Cambridge, MA: Harvard University Press.

Mignone, J., \& O’Neil, J. (2005). Social capital and youth suicide risk factors in first nations communities. Canadian Journal of Public Health, 96, S51-4.

Modie-Moroka, T. (2009). Does level of social capital predict perceived health in a community? A study of adult residents of low-income areas of Francistown, Botswana. Journal of Health, Population and Nutrition, 27(4), $462-476$.

Narayan, D., \& Pritchett, L. (1999). Cents and sociability: Household income and social capital in rural Tanzania. Economic Development and Cultural Change, 47(4), 871-897.

Perry, M., Williams, R. L., Wallerstein, N., \& Waitzkin, P.H. (2008). Social capital and health care experiences among low-income individuals. American Journal of Public Health, 98(2), 330-336.

Portes, A. (1998). Social capital: Its origins and applications in modern sociology. Annual Review of Sociology, $24,25$.

Putnam, R.D. (1993). The prosperous community: Social capital public life. American Prospect, 13, 35-42.

Rangihau, J. (1992). Being Maori. In King, M. (Ed.). Te Ao Hurihuri. Auckland: Reed Publishing.

Robert, S. A. (1999). Socioeconomic position and health: The independent contribution of community socioeconomic context. Annual Review of Sociology, 25, 489-516.

Royal Commission on Social Policy. (1988). The April Report. The Commission

Rush. (2002). Central obesity and risk for type 2 diabetes in Maori, Pacific, and European young men in New Zealand. Food and Nutrition Bulletin, 23(3; supp), 82.

Sachdev, P. (1990). Behavioural factors affecting physical health of the New Zealand Maori. Social Science Medicine, 30(4), 431-440.

Song, L., \& Lin, N. (2009). Social capital and health inequality: Evidence from Taiwan. Journal of Health and Social Behavior, 50(2), 149-63.

Utter, J., Denny, S., Robinson, E., Ameratunga, S., \& Milfont, T. L. (2011). Social and physical contexts of schools and neighborhoods: Associations with physical activity among young people in New Zealand. American Journal of Public Health, 101(9), 1690-5.

Voyle, J.A., \& Simmons, D. (1999). Community development through partnership: promoting health in an urban indigenous community in New Zealand. Social Science and Medicine, 49, 1035-1050.

Walker, P. (2007). Innovations in social welfare trust, risk and control within an indigenous-non indigenous social service partnership. Social Welfare, 16, 281-290.

Welshman, J. (2006). Searching for social capital: Historical perspectives on health, poverty and culture. The Journal of the Royal Society for the Promotion of Health, 126(6), 268-274.

Williams, D. R. (2012). Miles to go before we sleep: Racial inequities in health. Journal of Health and Social Behavior, 53(3), 279-95.

Wilson, W.J. (1996). When work disappears: The world of the new urban poor. New York: Alfred A. Knopf.

Wu, Q., Xie, B., Chou, C., Palmer, P. H., Gallaher, P. E., \& Anderson Johnson, C. (2010). Understanding the effect of social capital on the depression of urban Chinese adolescents: An integrative framework. American Journal of Community Psychology, 45(1-2), 1-16. 